\section{Barack Obama e Donald Trump: Uma análise dos determinantes domésticos da política externa estadunidense em relação ao Irã (2009-2018)}

Barack Obama and Donald Trump: An analysis of the domestic level in the United States Foreign Policy Towards Iran (2009-2018)

\section{Barack Obama y Donald Trump: Um analisis de los determinantes domésticos de la politica exterior estadunidense com relaciona a Iran}

Gustavo Fornari Dall'Agnol ${ }^{1}$

DOI: 10.5752/P.2317-773X.2019v7.n3.p7

Recebido em: 06 de setembro de 2018

Aceito em: 22 de outubro de 2018
1. Doutorando em Relações Internacionais pela PUC-MG. Residente em Belo Horizonte, Minas Gerais, Brasil. ORCID: 0000-0001-5566-0194. Contato: gustfd@gmail.com. (iD)

\title{
RESUMO
}

O presente artigo visa a analisar e explicar as diferenças na condução da política externa estadunidense para com o Irã dos governos de Barack Obama e Donald Trump. Para tal, recorre-se a análise empírica da política externa dos dois governos. Ademais, conceitos uteis da disciplina de Análise de Política Externa e da Ciência Política serão utilizados. Ver-se que as limitações impostas à política externa de Obama, advêm da pressão política exercida por grupos de interesse domésticos. Elites importantes, principalmente aquelas ligadas a vertente neoconservadora da política estadunidense, ao mesmo tempo em que restringiram a atuação de Obama no cenário internacional, são base de apoio para a política externa de Donald Trump e de seu partido, o Partido Republicano. A ruptura na política externa feita por Trump, pode ser compreendida através da análise desses grupos, o que fica evidenciado no caso do Irã.

Palavras-chave: Análise de Política Externa. Barack Obama. Donald Trump. Neoconservadorismo. Irã.

\section{AbSTRACT}

The present paper aims at analyzing and explaining the differences in the United States foreign policy conduct towards Iran in the governments of Barack Obama and Donald Trump. In order to do so, the paper rests on the empirical analysis of both governments. Beyond this, useful concepts of the disciplines of Foreign Policy Analysis and Political Science will be utilized as well. The study will de- 
monstrate that the limits imposed to Obama's foreign policy come from domestic pressures of interest groups. Important elites, mainly those with connections with the neoconservative vision of United States politics, at the same time that constrained Obama's action on the international system, are constitutive of the political basis and the Republican Party, that enables Trump's foreign policy. The ruptures put forward by Trump, can be understood through the analysis of these groups, fact that is shown in the case of Iran.

Key words: Foreign Policy Analysis. Barack Obama. Donald Trump. Neoconservatism. Iran.

\section{RESUMEN}

El presente artículo busca analizar y explicar las diferencias em la conduccí́on de la politica exterior estadunidense com relación a Irán em los gobiernos de Barack Obama y Donald Trump. Para eso, se recurre al análisis empírico de la politica exterior de los dos gobiernos. Además, conceptos útiles para la disciplina de Análisis de Política Exterior y de la Ciencia Politica seraán utilizados. Se notará que las limitaciones impuestas a la politica exterior de Obama, advienen de la presíon politica ejercida por los grupos de interés domésticos. Elites importantes, principalmente aquellas vinculadas a la vertiente neo-conservadora de la politica estadunidense, al mismo tempo em que restringiam la actuacíon de Obama em el escenario internacional, son base de apoyo para la politica exterior de Donald Trump y de su partido, el Partido Republicano. La ruptura em la politica exterior elaborada por Trump puede ser entendida a través del análises de esos grupos, lo que será evidenciado por el caso de Irán.

Palabras clave: Análises de Política Exterior; Barack Obama; Donald Trump; Neo- conservadorismo; Irán.

Introdução

O presente estudo busca realizar uma análise da política externa estadunidense no período de 2009 a 2018. Trata-se de uma análise comparativa entre os governos de Barack Obama e Donald Trump. Em vista da amplitude da temática em questão, delimita-se o artigo em torno da condução da política externa pelos dois governos com relação ao Irã. Parte-se do pressuposto que há diferenças substanciais nas relações com o Irã nos dois governos, demonstrado claramente pela documentação aqui discutida e os recentes desdobramentos em torno do acordo nuclear iraniano. Dessa forma, delineia-se um estudo de caso, cujo objetivo é compreender o porquê da diferença de política externa em relação ao Irã nos dois governos. Defende-se aqui a tese, de que a variação da política externa estadunidense com relação ao Irã (variável dependente), entre os governos Obama e Trump, pode ser explicada pela atuação dos grupos de interesse (variável independente), no período estudado.

Parte da problemática deste trabalho, passa, portanto, necessariamente, pelo debate dos componentes que definem a variação da política externa. Dedica-se a essa questão o primeiro tópico do estudo. Para tal, revisa-se alguns dos principais debates da disciplina de Análise de Política Externa. Argumenta-se que as variáveis domésticas são fundamentais para a compreensão da mudança ou continuidade da política externa. Alguns conceitos da área da Ciência Política, como os de elite e de intensidade desi- 
gual de preferências, também serão apresentados nesse tópico, de maneira a complementar o quadro conceitual do presente estudo. Dá-se especial atenção à análise dos grupos de interesse que conseguem afetar decisivamente o processo de tomada de decisão em política externa.

No segundo tópico, o presente trabalho busca realizar um breve balanço da política externa de Barack Obama e Donald Trump. Ver-se que as limitações domésticas a implementação da política externa, principalmente, devido a atuação de grupos de interesse. Além disso, as clivagens domésticas e a inclinação de determinadas vertentes da sociedade norte-americana ao conservadorismo, ajudam a explicar a ascensão de Donald Trump e a sua estratégia de política externa. Argumenta-se que a mesma é respaldada em interesses concretos do establishment estadunidense. Tal percepção fornece importantes insights sobre a política externa de Trump, conferindo mais previsibilidade e tangibilidade às suas ações, muitas vezes apontadas como, no mínimo, excêntricas, em análises mais jornalísticas que focam demasiadamente no papel do líder.

Finalmente, no terceiro e último tópico, analisa-se o caso do Irã. Através da análise documental; pesquisas de opinião pública; discursos; revisão de literatura e o mapeamento dos principais lobbies e think tanks, busca-se explicar as diferenças entre Obama e Trump para com o Irã. A ruptura de Trump, com relação ao seu antecessor na questão iraniana, pode ser explicada com base nos argumentos desenvolvidos nas secções anteriores, que são respaldados pela análise empírica do caso. Dessa forma, a tese aqui defendida é corroborada pela análise empírica do caso iraniano. Conclui-se que a atuação dos grupos de interesse explica, em grande parte, a dificuldade de Obama realizar uma política externa mais assertiva, conquistando resultados mais simbólicos do que concretos. Da mesma maneira, esses grupos proporcionam a Trump as bases necessárias para reverter a política externa de Obama, fato que se evidencia na análise do Irã.

Análise de Política Externa: Conceitos-chave

Antes de adentrar no tema propriamente dito do presente estudo, é mister analisar alguns conceitos e formulações teóricas relevantes para uma melhor compreensão do objeto em questão. A formulação de um viés analítico e estruturação da pesquisa passam, necessariamente, pela contribuição da literatura na área de Análise de Política Externa (APE), discutida de maneira sucinta nesse primeiro tópico. Na sequência, serão apresentados alguns conceitos fundamentais para a escolha das variáveis, dos atores e processos privilegiados neste trabalho.

Valerie Hudson (2014, p. 3-5) aponta que a subárea da APE tem como objetivo explicar (explanandum) as decisões tomadas por seres humanos que possuem consequências fora do Estado-nação. Essas decisões incluem ações, inações, reações em diferentes níveis envolvendo um largo escopo de atores. A autora define como o explanans da APE os fatores que influenciam o processo de tomada de decisão em política externa. A construção do campo de estudo da APE passa por uma transformação importante, principalmente com o fim da Guerra-Fria, ao contestar a premissa realista ${ }^{2}$, hegemônica no estudo das relações internacionais, de que
2. Waltz (1979) é considerado o fundador da vertente neorrealista, que viria a privilegiar as variáveis sistêmicas na análise das relações internacionais, tal vertente se tornaria a visão hegemônica na disciplina nos anos que se sucederam. 
3. A lógica de dois níveis foi introduzida por Putman (1988). 0 autor argumentou que existe um entrelaçamento entre os níveis doméstico e internacional na formulação da política externa que podia ser entendido por "jogos de dois níveis".

4. Para uma boa compreensão dos modelos que enfatizam os aspectos psicológicos na análise de política externa e tomada de decisão, ver: (MINTZ ROUEN, p. 97-121).

5. As traduções no presente estudo são próprias. o nível sistêmico deveria ser privilegiado na apreciação dos fenômenos de política externa. Ao abrir-se a "caixa-preta" do Estado como "unidade" ficou claro para os analistas que não é possível desvendar os fenômenos internacionais somente utilizando variáveis de nível sistêmico. Em confluência com tal perspectiva, o presente estudo confere importância às variáveis domésticas em sua análise.

O reconhecimento do nível doméstico como fundamental para compreender a APE suscita outro problema, a saber: dentro do nível doméstico, quais são as variáveis e unidades de análise a serem priorizadas, considerando a enorme gama de possíveis fatores domésticos que influenciam a política externa? Alex Mintz e Karl de Rouen (2010, p. 130) identificam cinco determinantes domésticos para a APE: a) ambiente econômico; b) interesses econômicos; c) opinião pública; d) ciclos eleitorais; e) jogos de dois níveis ${ }^{3}$. Hudson (2014, p. 34), por sua vez, destaca o papel do líder, das burocracias, das percepções culturais e identitárias, da dinâmica de grupos, de atributos nacionais, entre outros, como objetos de análise da APE. Já Hellen Milner (1994, p. 11), de maneira mais sucinta, destaca três fatores fundamentais: a) o interesse dos atores; b) as instituições domésticas; c) a distribuição de informação dentre os atores.

Além das supracitadas possíveis abordagens, pode-se mencionar os estudos que dão ênfase a aspectos psicológicos e cognitivo-comportamentais ${ }^{4}$. Julga-se necessário, no entanto, recortar o escopo do presente artigo de acordo com o considerado fundamental para atingir seu objetivo. Como trata-se da comparação da política exterior de dois governos, considera-se fundamental adentrar na composição dos governos e nas eventuais clivagens e alianças feitos por eles. Isso não significa que a variável sistêmica não seja importante para os fenômenos aqui analisados e nem se manterá constante, apenas não será trabalhada de maneira exaustiva no presente artigo. Ademais, opta-se por realizar uma análise baseada na identificação dos principais grupos de interesse e suas estratégias para com o tema em questão no período recortado.

De acordo com Milner (1994, p. 16) "quaisquer mudanças na agenda política possuem consequências distributivas e eleitorais." Diferentes grupos de interesse mobilizam-se e pressionam o governo de acordo com as suas preferências. A opção pela análise desses grupos deve-se ao fato de que a estratégia dos mesmos perpassa o ambiente institucional, o ciclo eleitoral, a economia, etc... Além disso, minorias organizadas podem ter mais influência do que as maiorias nos processos decisórios devido a intensidade desigual de preferencias apontada por Giovanni Sartori (1994, p. 301): "uma maioria intensa equivale a uma maioria ocasional. Os grupos pequenos, ao contrário, podem ser duradouros e igualmente intensos em relação a uma série de questões”. Ademais, há diversos grupos envolvidos no processo decisório em política externa. Para Sartori (1994, p. 304), "todas as decisões tomadas em uma sociedade política são antes examinadas, e realmente propostas por um comitê ou mais". Abdicar da análise desses grupos tornaria a análise incompleta. Esses grupos não são homogêneos e na maioria das vezes não representam os mesmos interesses. Há, portanto, disputas recorrentes na definição e implantação da agenda de política externa. De acordo com Hudson: 
Enquanto o jogo de relações internacionais pode ser jogado de acordo com o interesse nacional, há também um segundo jogo dentro de cada governo, um jogo de interesses e ambições organizacionais e pessoais, que pode de fato ser mais determinante da política externa de uma nação do que o jogo de interesse nacional (HUDSON, 2014, p. 101).

Dito isso, destaca-se que a principal unidade de análise no presente estudo são os grupos de interesse que conseguem exercer influência nas decisões relativas à política externa. Desse modo, evita-se também o economicismo, pois há também grupos organizados com objetivos diversos daqueles relacionados somente com a esfera econômica. No entanto, antes de adentrar em uma definição mais precisa desses grupos, faz-se necessária uma ressalva. Como o presente estudo compara a política exterior de Donald Trump e Barack Obama, cabe-se perguntar o porquê não focar-se-á nas características pessoais dos presidentes, objeto de muitas abordagens cognitivas. É evidente a importância da Casa Branca na definição da política exterior, já que muitas das ferramentas de política externa são mandatárias do chefe do executivo. No entanto, argumenta-se, aqui, que há um establishment na sociedade estadunidense que impede a livre ação do líder. De acordo com Hudson (2014, p. 73): "não importa o quão influente ou mercenário, um único líder não pode fazer e implementar política externa por sua própria conta. De fato, na maioria dos países, as decisões em política externa são sempre tomadas em grupo".

Hellen Milner destaca que o presidente é constrangido por diversas fontes domésticas em suas ações em política externa, como, por exemplo: a) opinião pública; b) grupos de interesse; c) Congresso nacional; d) agências governamentais; e) oposição partidária (MILNER, 2015). Milner, realiza um estudo sistemático de sete ferramentas da política externa, a saber: assistência econômica; comércio exterior; imigração; sanções; assistência geopolítica; definição do orçamento militar e envio de tropas ao exterior. Milner dá grande destaque aos grupos de interesse apontando que "A Constituição dos Estados Unidos foi escrita com de forma a contemplar o papel a ser desempenhado por grupos de interesse, e esses grupos vem exercendo um papel de destaque no sistema político estadunidense" (MILNER, 2015, p. 77). No entanto, a autora apresenta o argumento, em sua teoria de poder presidencial, de que nem todas as ferramentas de política externa sofrem a mesma influência desses grupos. Coletando dados de depoimentos perante o Congresso e registro de lobbies, a autora afirma que aquelas políticas de caráter mais distribucional e maior clivagem ideológica, a saber - comércio exterior, imigração, assistência econômica e definição do orçamento militar: tendem a sofrer grande influência de grupos de interesse. Já o envio de tropas ao exterior, assistência geopolítica e a imposição de sanções sofrem menos e, portanto, auferem maior liberdade para a atuação presidencial.

No presente estudo, contrapõe-se o argumento de Milner sobre a liberdade do executivo nessas ações de caráter "menos distributivo". Reconhece-se que o alto escalão do executivo possui maior liberdade institucional relativa para atuar nesses temas. No entanto, ressalva-se o papel fundamental do processo de constituição do alto escalão do exe- 
6. Para uma melhor compreensão da Teoria das Elites ver: BOBBI0, 2016. cutivo e da própria formulação da agenda desses temas. A constituição do alto escalão do executivo é um processo que vem de antes das eleições e se estende até o final do mandato. O processo envolve estruturas partidárias, empresas financiadoras, negociações com um amplo leque de grupos de interesse, entre outros. A formulação da agenda é objeto de constante disputa, como aponta Hudson (2014, p. 106) "A manipulação de agendas coletivas é uma habilidade premiada na arena política". Setores midiáticos, lobbies, think tanks e opinião pública são apenas alguns exemplos que influenciam diretamente a agenda do executivo. No terceiro tópico deste estudo, investiga-se o caso do Irã e como grupos de interesse possuem diferentes perspectivas sobre esse país, quais ações devem ser tomadas e como essas perspectivas influenciam as decisões do alto executivo. A diferença é que o lobbie ocorre de maneira mais indireta e menos computável nesses casos. A pressão direciona-se à Casa Branca em termos de projetos mais "gerais". Em relação a essa pressão, Milner (2015) aponta que:

$$
\begin{aligned}
& \text { A Casa Branca é mais facilmente alvo quando a temática concerne a direções } \\
& \text { políticas mais amplas. Quando essas decisões são feitas, nas quais o presidente } \\
& \text { estará envolvido ativamente, as decisões orçamentárias que possuem caráter } \\
& \text { distribucional aflorarão (MILNER, 2015, p. 105). }
\end{aligned}
$$

Mapear os grupos de interesse que afetam o processo de tomada de decisão é tarefa árdua. Complementar à discussão até agora apresentada é o instrumental analítico da Ciência Política, e, em especial, à Teoria das Elites. A teoria das elites surgiu na Itália no final do século XIX. Seus principais precursores e expoentes foram Gaetano Mosca e Vilfredo Pareto. Mosca, através de duas obras Sobre a Teoria dos Governos e Sobre o Governo Parlamentar, publicada em 1884, e Elementos de Ciência Política (1896) foi o primeiro a delinear a teoria. Tanto Mosca quanto Pareto, inspirados pelo positivismo, buscavam auferir cientificidade a Ciência Política através da observação empírica e coleta de documentos históricos com vista a desenvolver leis gerais ${ }^{6}$. A existência de uma minoria governante e uma maioria governada na evolução das sociedades, resultado da observação empírica dos autores, era passível de generalização. Mosca, Pareto e a Teoria das Elites foram marginalizados na Ciência Política por se colocarem céticos a mudanças revolucionárias e até mesmo a possibilidade da democracia.

Muito embora a conceituação de elite possa resultar em uma análise conservadora, isso não é necessariamente imperativo. Haja visto que, segundo Bobbio "Um dos maiores temas da análise política e, tudo somado, talvez o mais significativo, é determinar quem governa realmente uma dada sociedade" (BOBBIO, 2016, p. 222-223). Muitos autores não conservadores, como Gramsci e Charles Wright Mills, enfrentaram tal problemática. Entende-se, neste estudo, o conceito de elite, desenvolvido por Charles Wright Mills da seguinte forma:

A elite que ocupa os postos de comando pode ser considerada como constituída de possuidores de poder, da riqueza e da celebridade (...) a ideia de elite como composta de homens e mulheres com um caráter moral mais apurado é uma ideologia de elite em sua condição de camada dominante privilegiada, e isso é válido tanto quando a ideologia é feita pela própria elite ou quando outros falam por ela (MILLS, 1981, p. 13-14). 
A análise feita por Mills em seu livro Elites do Poder sobre a alta sociedade estadunidense, pode contribuir bastante para guiar a pesquisa empírica. Mills (2000, p. 4), não só identificou que, nos Estados Unidos, "a base do poderio nacional está hoje nos domínios econômico, político e militar" como também realizou uma análise empírica de grande folego sobre quem compunha tais elites. Mills observou que as elites se intercambiavam entre esses três setores, com generais comandando empresas, empresários no alto escalão do governo e por assim em diante. Isso auferia as elites um maior grau de coesão, o que é de suma importância para a analisar o processo decisório em política externa. Conforme discutido anteriormente, reconhece-se a complexidade envolvida na análise dos fenômenos internacionais, bem como a imensa gama de atores domésticos envolvidos na formulação da agenda e na implantação da política externa. No entanto, pressupõe-se e se argumenta que, para a elaboração da agenda e implementação da política externa, faz-se necessário um alto grau de coesão entre as elites do país, conforme apontam Milliband (1982), Dreifuss (1987) e Schweller (2006). Portanto, principalmente quando se trata de temas estratégicos, como no presente artigo, espera-se que para o sucesso de quaisquer políticas haja um grau de coesão suficiente entre as elites.

Antes de adentrar na problemática e na empiria de fato, fez-se necessário, para melhor atingir o objetivo do presente estudo, retomar alguns debates e desenvolvimentos conceituais da disciplina da Análise de Política Externa. Destacou-se que, para compreender a variação da política exterior entre o governo Obama e Trump, é fundamental investigar o nível doméstico. Haja vista todas as possíveis abordagens e todos os atores domésticos que poderiam ser pesquisados, optou-se pela análise dos grupos de interesse. Além disso, recorreu-se à Mills para argumentar que grupos de interesse do alto escalão militar, econômico e político possuem um nível de coesão que os permite implementar ações na política externa. Desse panorama, surge, no entanto, um questionamento: como instrumentalizar esses conceitos para a realização de uma análise empírica? Ou seja, como mapear a importância desses grupos de interesse, principalmente as elites econômica, política e militares na variação da política externa? Do ponto de vista deste trabalho é possível correlacionar a atuação desses grupos de interesse com a variação da política externa através da análise de, por exemplo: documentos-chave; contratos; discursos e dados econômicos. Será realizada, no tópico a seguir, uma análise mais geral da política externa dos governos Trump e Obama, que já nos permite situar melhor a atuação de determinados grupos de interesse.

A Política Externa de Barack Obama e a Ascensão de Donald Trump.....

No presente tópico, discute-se primeiramente as diretrizes gerais da política externa do governo Obama (2009-2017) na perspectiva de identificar os principais grupos de interesse e forças domésticas que compunham a formulação da agenda e processo de decisão desse governo. Para tal, recorre-se a alguns documentos como a Plataforma do Partido Democrata, discursos presidenciais, as National Security Strategies do governo, entre outros dados de composição do Congresso e do Executivo, bem como 
7. Disponível em: <http://www.americanrhetoric.com/speeches/convention2008/barackobama2008dnc.htm>. Acesso em: 20 de jun. 2015 dados econômicos. Posteriormente, a luz desses documentos, retoma-se a literatura especifica sobre a política exterior de Obama e as análises e documentos pertinentes para compreender o início do governo Trump e sua política externa. Dessa forma, espera-se traçar um panorama geral da política externa de Obama e identificar as possíveis rupturas de Donald Trump com ênfase nos grupos de interesse domésticos.

\section{Campanha, posse e composição da equipe}

A conjuntura na qual Barack Obama foi eleito e tomou posse sinalizava importantes desafios para o novo presidente. Os Estados Unidos estavam no auge da maior crise financeira desde 1929, a ameaça do desenvolvimento de armas nucleares pela Coréia do Norte e o Irã havia se intensificado, as guerras no Iraque e no Afeganistão mostravam-se infrutíferas, o desafio imposto pelo conflito Israel-Palestina aumentava, bem como as tensões entre o Paquistão e a Índia e, finalmente, a Rússia mostrava claros sinais da pretensão de retomar a influência sobre os antigos territórios soviéticos (BROWN, 2015; LAIDI, 2012). Tal foi o cenário em que o governo Obama construiu suas principais diretrizes de campanha e de governo.

Em sua campanha, conforme exemplificado em seu discurso de aceitação da nomeação para presidenciável pelo Partido Democrata ${ }^{7}$, Obama teceu duras críticas à política exterior de seu antecessor, ratificando o que chamou de desperdício de recursos no Iraque e falta de um objetivo claro na ocupação do Afeganistão. Quanto a isso, consonante com sua campanha, Obama (2009, p. 4) afirmou em seu discurso de posse que "Iremos responsavelmente deixar o Iraque para seu povo e forjar uma paz duramente conquistada no Afeganistão". A tônica do discurso de Obama pautava-se pela multilateralidade nas relações exteriores e pela conciliação, mas, principalmente, pelo pragmatismo.

No anúncio da composição do alto escalão responsável pela política externa e segurança, importantes indícios de grupos de influência doméstica podem ser identificados. Para Secretário de Defesa, Obama manteve Robert Gates, que havia servido George W. Bush e era um importante nome no establishment militar, pois já havia sido Diretor da Central Intelligence Agency (CIA) e trabalhado no National Security Council (NSC). Obama defendeu tal decisão argumentando que "quando se trata de segurança não somos democratas ou republicanos, somos americanos" (OBAMA, 2009 , p. 4). Na mesma linha, Obama indicou para o cargo de Assessor de Segurança Nacional James Jones, comandante militar que, no entanto, não havia experiência política. Para Secretária de Estado, Obama nomeou Hillary Clinton, sua antiga adversária nas primárias, provavelmente na tentativa de garantir uma boa coesão interna no partido.

\section{A política externa de Obama: um breve balanço}

Em relação aos principais desafios impostos pela conjuntura internacional e doméstica acima apresentados, boa parte da literatura aponta que Obama não obteve bons resultados, não é possível identificar uma "Doutrina Obama" e suas conquistas internacionais são limitadas e sim- 
bólicas. Com relação ao Iraque, por exemplo, Obama foi bem-sucedido no sentido de cumprir sua promessa de retirar as tropas estadunidenses do país, fato que ocorreu em dezembro de 2011. No entanto, o Iraque pós-guerra mostrou-se prejudicial aos interesses dos Estados Unidos na região, vide a eventual ascensão do Estado Islâmico. Zaki Laidi (2012, p. 151) aponta ainda que com a saída dos Estados Unidos do Iraque, a influência do Irã em Bagdad aumentou consideravelmente. Esse resultado destoa ainda dos objetivos apontados na National Security Strategy de $2010^{8}$, no qual o governo de Obama defende uma transição pacífica e uma cooperação de longo prazo com o Iraque após a remoção das tropas.

No caso do Afeganistão, o governo conseguiu cumprir seus objetivos de maneira mais clara. Com o envio de mais tropas, Obama conseguiu vitórias simbólicas como o recuo do Talibã e a morte de Osama Bin Laden. Todavia, a custosa guerra ao terrorismo na díade Afeganistão-Paquistão não forneceu vitórias estratégicas e significativas. Também com relação ao Oriente Médio, a NSS (National Security Strategy) 2010 e a NSS 2015 identificam como prioritário para a estabilidade da região a resolução do conflito Israel-Palestina, com o qual o governo Obama advogou por uma solução de dois Estados, gerando tensões com Israel e sendo infrutífero ao final de seu mandato. Em resposta a uma declaração de Obama de que as fronteiras de Israel e Palestina deveriam voltar aquelas anteriores a 1967, o Primeiro Ministro Benjamim Netanyahu viajou a Washington e falou diante o Congresso, com apoio de lobbies internos pró-Israel, para que se opusessem à posição da Casa Branca, enfraquecendo a posição de Obama.

Outra prioridade enfatizada pela equipe de Obama e que possui conexões com grupos de interesse domésticos é a questão ambiental. O governo se engajou, desde a campanha, com a questão do aquecimento global. Na NSS 2015, a questão ambiental e, em especial, o aquecimento global, consta dentre as Top Security Priorities já que, de acordo com o documento: "O aquecimento global é uma ameaça urgente e crescente para nossa segurança nacional, contribuindo para aumentar desastres naturais, ondas de refugiados, e conflitos por recursos básicos como água e comida" (NATIONAL SECURITY STRATEGY ARCHIVE, 2015, p. 12). Laidi (2012) aponta que após as eleições congressuais de 2010, no entanto, com o Partido Republicano obtendo maioria na House of Representatives, a atuação de Obama na área ambiental ficou restringida pela oposição doméstica e o governo não avançou substancialmente nessa agenda. Cabe destacar, no entanto, que o governo Obama teve importante papel na Conferência de Paris, assinando o acordo e se comprometendo em cumpri-lo através de uma ordem executiva. Ao centralizar o acordo no executivo, todavia, buscando se desviar das pressões domésticas, a suposta vitória de Obama na agenda ambiental sofreu forte oposição interna e se fragilizou.

De acordo com Laidi (2012, p. 34), "o multilateralismo de Obama claramente acaba nos portões da Organização Mundial do Comércio (OMC) ". O autor argumenta que a saída dos Estados Unidos das negociações da Rodada Doha se deve ao fato de que muitos lobbies fortes, inclusive ligados ao eleitorado de Obama, como o Farm Bureau (ligado ao agronegócio) e sindicatos de indústrias tradicionais como as de aço, têx-
8. Disponível em: <http://nssarchive. us/national-security-strategy-2010/>. Acesso em: 20 de jun. 2018 
9. Dados sobre os PACs, bem como detalhamento da função dos mesmos no processo eleitoral estão disponíveis em: $<$ https://www.opensecrets.org/pacs/index.php?cycle=2016\&party=A $>$. Acesso em: 20 de jun. 2018 til e carvão são altamente organizados institucionalmente e se opõem à abertura comercial. Nesse sentido, tanto Sartori, discutido anteriormente -ao falar da intensidade de preferências- e Milner, ao argumentar sobre os efeitos distributivos da política externa e os grupos de interesse domésticos, são contemplados pela análise empírica. A não ratificação do Tratado da Trans-Pacific Alliance (TPP) pelo Congresso pode ser explicada pelo mesmo motivo e enfraqueceu a política comercial do governo Obama.

Com relação aos efeitos distributivos na definição da política externa, conforme apontado por Milner (2015), outra pauta de alta influencia por grupos de influência doméstica é a definição do orçamento militar, que passa, necessariamente, pela aprovação do Congresso. No governo de George W. Bush, entre seu ano fiscal de 2002 e o último ano de seu mandato em 2008 aumentou o orçamento anual de aproximadamente \$312 milhões para \$621 milhões como observado no gráfico abaixo (Gráfico 1). Tal variação representa uma variação de $100 \%$ do orçamento anual, ou seja, uma forte tendência militarista do governo republicano.

\section{Gráfico 1- Evolução dos Gastos Militares em US\$ Correntes 2001-2016 (Em Milhões)}

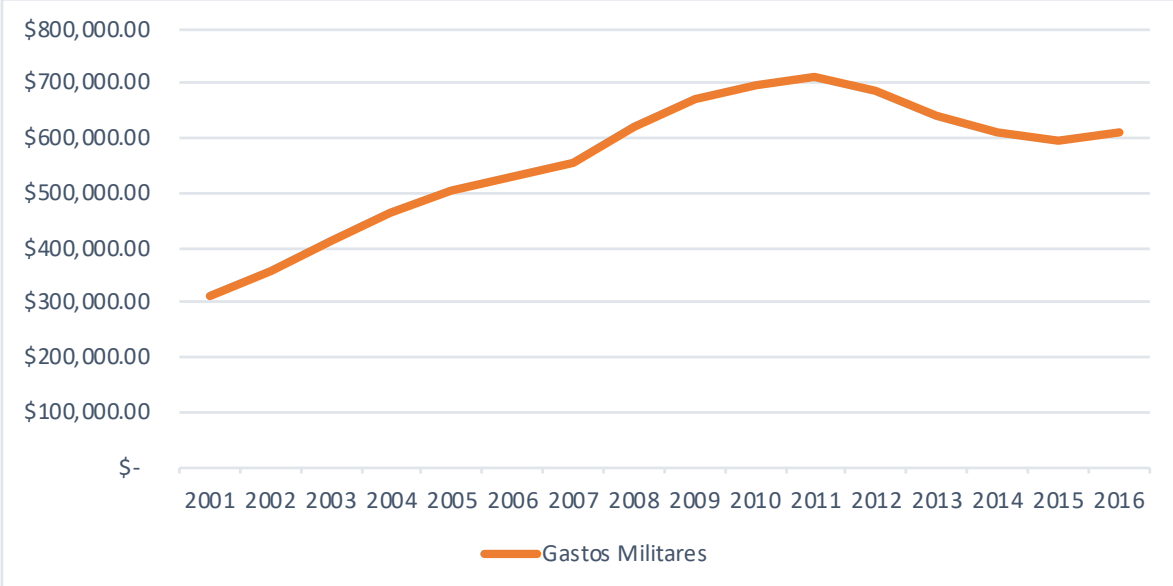

Fonte: STOCKHOLM INTERNATIONAL PEACE RESEARCH INSTITUTE, 2018.

Já o governo Obama, de discurso e vertente mais multilateralista, reduziu o gasto anual militar nominal de aproximadamente $\$ 668$ milhões em seu primeiro ano fiscal (2009) para \$611 milhões no último ano de seu mandato. Tal fato também está intimamente relacionado com os grupos de interesse. No ciclo eleitoral de 2015-2016, por exemplo, as quatro maiores empresas de armamentos dos Estados Unidos- Boeing, Lockheed Martin, Northrop Grumman e General Dynamics- através de seus respectivos Political Actions Commities (PACS) doaram mais de 60\% de seus recursos destinados para o lobbie para candidatos republicanos ${ }^{9}$. Esses indícios não significam somente que os republicanos possuem tendências mais militaristas, mas que também, os governos democratas estarão amarrados por grupos de interesse no Congresso em temas não só de definição do orçamento militar, mas também de ajuda geopolítica e temas de segurança de maneira mais geral. Milner (2014), ao analisar depoimentos perante o Congresso, não encontrou provas de influência de grupos de interesse em temas como ajuda geopolítica, no entanto, a autora admite que 
"possa ser, por exemplo, que o Congresso não queira chamar fabricantes de armamentos para depor com relação a temas como ajuda geopolítica" (MILNER, 2015, p. 115). Espera-se que o governo Trump tenha tendências militaristas ainda maiores que as de Obama e que, em conformidade com o que foi visto até o momento, grupos de interesse influenciem diversos aspectos de sua política exterior. Tal fato pode ajudar a conferir maior tangibilidade à análise de sua política externa.

\section{Grupos domésticos e a ascensão de Donald Trump}

A atuação de grupos domésticos, representado também pela perda de maioria congressual, constrangeu a atuação internacional de Obama. Nesse sentido, a retórica apresentada por Trump em sua campanha, refletida no slogan "Make America great again" acusou os resultados da política internacional de Obama de permissivos com os inimigos, enfraquecendo o poder dos Estados Unidos. O brevíssimo balanço da política exterior de Obama revelou algumas das limitações. Faz-se, agora, uma análise de caráter mais conjectural da política externa de Trump, haja vista que seu governo é muito recente para uma análise aprofundada.

Entende-se que Donald Trump e seu governo não são alienígenas na estrutura de poder e riqueza norte-americanas, mas são produto de um establishment há muito tempo consolidado naquele país. Dessa forma, a sua política externa, bem como sua condução econômica interna, não é tão volátil ou imprevisível como jornais e alguns think tanks alarmam. Para responder se, de fato, há uma "Doutrina Trump", desse modo, é necessário ir além das declarações de um homem, no mínimo excêntrico, e analisar os principais grupos de interesse que sustentam o seu governo. Alguns documentos são cruciais para tal empreitada, a começar pela Plataforma do Partido Republicano (PPR), publicado na convenção nacional do partido antes da confirmação da vitória de Donald Trump nas primárias. No documento supracitado estão delineadas as principais pautas e prescrições encontradas na política externa de Donald Trump. A plataforma traça uma conjuntura que remete ao início dos anos 1980, argumentando que os Estados Unidos estão enfraquecidos diante do fortalecimento de seus inimigos e que haviam [os Estados Unidos] voltado aos "dias de poder irrelevante de Jimmy Carter" (PLATAFORMA DO PARTIDO REPUBLICANO, 2016, p. 41) devido à negligência dos governos democratas. Dessa forma, os republicanos se comprometem em "reestabelecer o poder bélico norte-americano como o maior do mundo, com vasta superioridade sobre qualquer outra nação ou grupo de nações do mundo" (PLATAFORMA DO PARTIDO REPUBLICANO, 2016, p. 41). A conjuntura internacional é descrita, ainda, como iminentemente perigosa em que a Rússia e a China avançam seus interesses, grupos terroristas desestabilizam o Oriente Médio e ameaçam o Ocidente, Estados párias (rogue states), especialmente Irã e Coréia do Norte, desequilibram as regiões e infligem a ameaça de um ataque nuclear iminente.

Mais elucidativa é a parte prescritiva do documento. Em outra referência aos anos 1980, os republicanos advogam uma resposta conforme a de Ronald Reagan, ou seja, peace through strength, um dos quatro pilares 
10. As ideias do presente tópico foram primeiramente desenvolvidas em Dall'Agnol (2018). formulados na National Security Strategy de Donald Trump, publicada em dezembro de 2017. O aumento dos gastos militares e, em especial, a retomada da Ballistic Missile Defense (BMD) são dados como prioridades para atingir a paz através da força. Outras assertivas, como o excepcionalismo norte-americano e o "novo século americano", também não são novidades. Em termos mais concretos, o documento advoga a saída do acordo nuclear com o Irã e o apoio inequívoco a Israel: "Nós reconhecemos Jerusalém como a eterna e indivisível capital do Estado Judeu e defendemos que a embaixada norte-americana seja transferida para lá em cumprimento com a lei dos Estados Unidos" (PLATAFORMA DO PARTIDO REPUBLICANO, 2016, p. 47). A plataforma defende o rearmamento do Japão e da Coréia do Sul, com a inclusão de sistemas BMD nos mesmos, devido à ameaça nuclear norte-coreana. Digno de nota, também, é a reprovação do reestabelecimento das relações com Cuba mencionada pelo Partido. Em suma, as 66 páginas do documento são uma espécie de previsão do que viria a ser o primeiro ano do governo de Donald Trump.

A condução do governo Trump, de acordo com as prerrogativas da Plataforma, não foi feita somente pela filiação ao Partido, mas do triunfo de um projeto mais antigo no qual segmentos importantes da elite dos Estados Unidos buscam consolidar um ciclo virtuoso de acumulação de poder e riqueza. Com isso, Trump é uma manifestação da coesão entre o capital financeiro, o complexo-industrial militar e think tanks que ascenderam ao poder com sucesso nos anos Reagan e consolidaram o neoconservadorismo como importante força política no cenário estadunidense. O neoconservadorismo tem como principais pilares: o nacionalismo em forma da crença na grandeza e superioridade dos Estados Unidos; o unilateralismo; o internacionalismo não institucional (intervencionismo); o militarismo e a defesa da livre iniciativa privada (TEIXEIRA, 2010, p. 53-74). Apresenta como principais expoentes intelectuais Robert Kagen e William Kristol. Trata-se, portanto, da fusão entre uma espécie de keynesianismo militarista e neoliberalismo, o que, na prática, significou a transferência dos recursos sociais para o setor militar nos anos 1980. Muito embora, na retórica, Donald Trump tenha defendido o que analistas chamaram de um "novo isolacionismo", as suas ações em política externa, política econômica e sua recente NSS, expressam uma adesão clara ao neoconservadorismo. Como apontado por Melvyn P. Leffler, na Foreign Affairs, a NSS de Trump está longe de ser isolacionista, propondo engajamento para todas as regiões do mundo (LEFFLER, 2017). Cumpre-se destacar, ainda, que o neoconservadorismo perdeu influência na agenda política com o fim da Guerra-Fria, período em que se tornou patente a identificação de novos inimigos para promover a agenda militarista e patriótica do país. ${ }^{10}$

É, pois, exatamente na identificação de um mundo hostil, hobbesiano, que o pilar "Peace Through Strength" do NSS de Trump inicia sua análise do sistema internacional: "a continuidade central na história é a disputa pelo poder. A atualidade não é diferente (NATIONAL SECURITY STRATEGY ARCHIVE, 2017. p. 25). Assim como Reagan afirmou que a União Soviética estava ultrapassando as capacidades dos Estados Unidos devido ao descaso dos democratas e, em especial, Jimmy Carter, o 
NSS de Trump traça um cenário no qual os Estados Unidos perderam sua vantagem no mundo pós-Guerra Fria devido à negligencia dos governos anteriores e, em especial, os de Barack Obama. O documento aponta três fontes de ameaças: os poderes revisionistas, a saber, a China e a Rússia, os Estados páreas (Irã e Coréia do Norte) e organizações internacionais terroristas. Em termos prescritivos, o documento não destoa da Plataforma do Partido substancialmente, muito embora prescreva prioridades para uma imensa gama de temas e países do mundo, o que levou a analista Rebecca Lissner a qualificar o documento como "um exercício de retórica, caracterizado por ambições grandiosas e uma longa lista de prioridades" (LISSNER, 2017). No entanto, o que fica claro no documento é a adesão aos princípios neoconservadores e a ruptura com a retórica multilateralista de Obama. Para Leffler, o documento espelhou o pensamento de Dick Cheney (ex vice-presidente) e Paul Wolwowitz (conselheiro de George W. Bush). Diante disso, o alinhamento do governo ao neoconservadorismo pode ser percebido, também, através do apoio da Heritage Foundation, influente think tank conservador, ao governo. Argumenta-se, aqui, que o projeto de governo necessita de uma base material sólida, para além do apoio popular, a fim de se sustentar. A começar pelo setor militar, Trump solicitou ao Congresso um orçamento de $\$ 700$ bilhões a ser gasto em defesa no ano de 2018. O militarismo dos neoconservadores beneficia, primeiramente, aos conglomerados militares, como a Huntington Ingalls, Lockheed Martin, Northrop Grumman e Boeing, que poderão fabricar para o governo, respectivamente, submarinos, mísseis lançados de submarinos, bombardeadores e navios cargueiros (THOMPSON, 2016). Outras indústrias expressivas, como as de petróleo, carvão, construção, farmacêutica e o setor financeiro fazem parte da base de apoio de Donald Trump devido ao relaxamento do governo nas regulamentações ambientais e fiscais (HEATH, 2016). Em especial a questão ambiental, vê-se claramente uma ruptura entre Trump e Obama, em vista de que os dados de PAC's no ciclo eleitoral de 2015-2016, por exemplo, apontam que as maiores empresas do setor de petróleo estadunidense - Exxon Mobil e Chevron- doaram 90\% de seus recursos de campanha para republicanos. Esse cenário ajuda a compreender a retirada do Acordo de Paris, por Donald Trump.

Os grupos de interesse até o presente momento mencionados explicam, em larga medida, as limitações da atuação de Obama e as medidas recentemente adotadas por Trump. Argumenta-se que a análise das elites, ou de maneira mais geral dos grupos de interesse, é fundamental para compreender simultaneamente rupturas e continuidades na política externa. Algumas ações que não são tão obviamente ligadas aos interesses domésticos, como o envio de tropas, sanções e ajuda geopolítica, conforme apontado por (MILNER, 2015) também podem ser compreendidas com auxílio da análise de grupos de interesse. Na próxima secção, adentra-se no estudo de caso do presente estudo, a saber, política estadunidense para com o Irã nos governos de Obama e Trump. Dessa forma, vê-se de maneira mais objetiva a atuação de alguns lobbies e infere-se que o resultado da política estratégica também é resultado de grupos de interesse institucionalmente organizados, como a análise das plataformas partidárias demonstra. 
11. Os fatos históricos da presente sessão são retirados de duas linhas do tempo a primeira preparada pelo jornal Al Jazeera disponíve em: <https://www.aljazeera.com/ FOCUS/IRANAFTERTHEREVOLUTION/2009/02/2009249123962551.

HTMLL.Acesso em: 14 de jun. 2018

E a segunda pela agência Reuters disponível em: <https://www.reuters. com/article/iran-nuclear-usa-timeline/ timeline-u-s-iran-relations-from-1953-coup-to-2016-sanctions-relief-idUSL2N1500R1>. Acesso em: 14 de jun. 2018

12. 0 presente estudo não possuí como objetivo desenvolver uma análise histórica das relações Estados Unidos- Irã. Para tal, recomenda-se Murray (2016): Kinch (2016).
Relações Estados Unidos- Irã (2009-2018): Um estudo de caso

Alguns antecedentes históricos são de suma importância para compreender a política-externa estadunidense com relação ao Irã. Faz-se uma breve linha do tempo para auxiliar na compreensão do período mais recente tratado aqui. Posteriormente, discute-se a política externa do governo Obama para o Irã e, em especial, o acordo nuclear iraniano. Por fim, analisa-se os motivos de ruptura no tratamento com o Irã por parte de Donald Trump, enfatizando a saída do referido acordo por parte dos Estados Unidos.

\section{Antecedentes históricos}

Em 1951, Mohammad Mosadeq, de vertente nacionalista, assume como Primeiro-Ministro no Irã. Poucos dias após a sua posse, Mosedeq nacionalizou o petróleo. Tal falto, marcou o início das tensões entre o Irã e os Estados Unidos. No entanto, apenas dois anos depois, as inteligências britânica e estadunidense apoiaram um coup por uma cúpula militar para restituir o poder dos Xáas ${ }^{11}$. Os anos que se seguiram foram de alinhamento com os Estados Unidos por parte do Irã, inclusive na área nuclear, quando, por exemplo, em 1968, o Irã assinou o Tratado de Não Proliferação Nuclear (TNP). As relações se deterioraram de fato, quando, em 1979, a Revolucão Iraniana forçou para o exílio os Xáas apoiados pelos Estados Unidos e o exilado há 14 anos no Iraque, o líder religioso Ayatollah Ruhollah Khomeini retornou ao Irã e se tornou o Líder Supremo. Ao mesmo tempo, demandando a volta dos Xáas para julgamento, estudantes iranianos sitiaram a embaixada estadunidense e mantiveram lá sessenta e três reféns, crise que iria durar mais de um ano, até a posse de Ronald Reagan no dia 21 de janeiro de 1981.

A partir da Revolução Iraniana as relações entre os dois países nunca mais viriam a se normalizar. Os anos 1990 são marcados por inúmeras sanções impostas pelos Estados Unidos, quando, a partir de 1995, o presidente Bill Clinton acusou o Irã de patrocinar o terrorismo e planejar adquirir armamentos de destruição em massa. As sanções se destinavam ao comércio com o Irã, e principalmente, à exportação de petróleo. Em 1996, Clinton anunciou que iria penalizar qualquer empresa que investisse mais de $\$ 40$ milhões de dólares anuais no Irã. Nos anos de George W. Bush, as tensões se acirram ainda mais devido do programa nuclear iraniano e o desenvolvimento de fato de reatores nucleares. Bush acusou o Irã de fazer parte do "eixo do mal" juntamente com a Coréia do Norte e o Iraque, em 2002. Durante os anos Bush, em diversos discursos, o presidente não abriu mão da possível utilização da força contra o Irã. Em setembro de 2008, na disputa eleitoral, o então candidato Barack Obama prometeu uma espécie de "recomeço" nas relações com o Irã e disse que estava aberto a negociações. Quando Obama foi eleito, o então presidente iraniano Almadinejad o parabenizou ${ }^{12}$.

\section{Obama, Trump, o Irã e o acordo nuclear}

Na Plataforma do Partido Democrata, de 2008, está expresso que "o mundo precisa prevenir que o Irã adquira armas nucleares. Isso começa com sanções mais duras e diplomacia de alto nível, sem pré-condições" (PPD, 2008, p. 31). O documento apresenta para o Irã duas opções: 
Iremos oferecer ao Irã uma escolha clara: se você abandonar seu programa de armas nucleares, o apoio ao terrorismo e as ameaças a Israel, você irá receber incentivos significativos, caso contrário, os Estados Unidos e a comunidade internacional irá aumentar a pressão, com sanções unilaterais mais severas, sanções multilaterais mais duras dentro e for a do Conselho de Segurança das Nações Unidas, e uma ação continua para isolar o regime iraniano (PLATAFORMA DO PARTIDO DEMOCRATA, 2008, p. 31).

A NSS, de 2010, reforça essa posição, apontando o Irã como prioridade máxima de segurança. O documento afirmava que o Irã desestabilizava o Oriente Médio, ameaçava Israel, apoiava o terrorismo e era uma ameaça para a paz mundial. Cabe-se mencionar a Declaração de Teerã, assinada por Brasil, Turquia e Irã no dia dezessete de maio de 2010. Nessa proposta, o Irã transferiria seu estoque de urânio levemente enriquecido, à época 1.200 quilos, para a Turquia. Em troca, as sanções seriam abandonadas e o Irã poderia receber 120 quilos de combustível para seu reator de pesquisa. A iniciativa tripartite, no entanto, foi frustrada pelo CSNU, que já no dia 9 de junho, aplicou mais sanções ao Irã, desta forma, ignorando a Declaração. Alguns eventos e mudanças de relações entre Washington e Tel Aviv, no entanto, norteariam os eventos para um caminho mais favorável a esse tipo de acordo.

Em 2013, a eleição de um presidente considerado mais pragmático no Irã, Hassan Rouhani, com uma plataforma de campanha pautada pela recuperação da economia ${ }^{13}$, gravemente afetada pelas sanções, abriu uma possibilidade de diálogo para Obama, que conversou com Rouhani pelo telefone em setembro de 2014, o contato de mais alto nível entre os dois países em mais de três décadas. Em novembro do mesmo ano, o grupo formado por Estados Unidos, Rússia, China, França, Inglaterra, Alemanha - grupo conhecido como P5 +1 , os cinco membros do CSNU mais a Alemanhainiciam uma série de negociações com o Irã que iria culminar no Joint Comprehensive Plan of Action de julho de 2015, ou o "acordo nuclear iraniano".

O Joint Comprenhensive Plan of Action (JCPA) foi um acordo no qual o Irã se comprometia a limitar suas atividades nucleares e permitir a inspeção regular delas em troca da suspensão das sanções impostas à sua economia. O Irã se comprometeu em reduzir drasticamente o número de centrífugas, limitar o nível de enriquecimento de urânio para níveis mínimos, abrir mão de reatores nucleares e concordar com a inspeção periódica pela Agência Internacional de Energia Atômica (AIEA). Em troca, o Irã poderia retomar o acesso ao mercado financeiro internacional e as sanções sob suas exportações de petróleo seriam retiradas. ${ }^{14}$ A NSS, de 2015, já reflete tal processo, pois assume uma postura mais otimista em relação a de 2010, destacando o sucesso da combinação estratégica de sanções e diplomacia linha dura imposta pelos Estados Unidos.

Benjamim Netanyahu, com apoio de diversos membros do Congresso dos Estados Unidos, se opôs ao acordo, taxando o mesmo como "um erro histórico", já que, para o premier israelense, Teerã havia conseguido o alívio das tensões a base de ameaças (BROWN, 2015, p. 692). Isso já havia sido motivo de disputa entre Obama e Netanyahu, pois o último apoiava a destruição via bombardeio das plantas nucleares iranianas, enquanto Obama insistia por via da negociação dura. A literatura destaca que o lobbie judaico, principalmente através da American Israel Public Action Committee (AIPAC) limitou a atuação de Obama no Oriente Médio. Muito embora
13. Disponível em: <https://www. reuters.com/article/iran-nuclear-usa-timeline/timeline-u-s-iran-relations-from-1953-coup-to-2016-sanctions-relief-idUSL2N1500R1>. Acesso em: 14 de jun. 2018.

14. Para mais informações sobre o JCPA ver: https://www.bbc.com/news/world-middle-east-33521655. 
15. Informações disponíveis em: $<$ https://www.nytimes.com/2018/05/08/ world/middleeast/trump-iran-nuclear-deal.html>. Acesso em: 16 de jun.

16. Ver em: <https://www.theguardian com/world/2018/may/08/iran-deal-trump-withdraw-us-latest-news-nuclear-agreement>. Acesso em: 16 de jun. 2018.

17. Disponível em: <https://www heritage.org/middle-east/commentary/ trump-was-right-terminate-the-iran-deal>. Acesso em: 16 de jun. 2018 o JPCA pudesse ser considerado um sucesso diplomático, o mesmo não respaldou o apoio de importantes grupos domésticos e não ganhou força de Tratado, fato que limitou sua eficácia.

A falta de ratificação congressual levou o Partido Republicano, em sua PPR 2016, a tecer duras críticas a Obama. O documento afirma que os acordos climáticos e o do Irã seriam revistos (PLATAFORMA DO PARTIDO REPUBLICANO, 2016, p. 26). O documento vai além e afirma que o executivo do democrata Obama foi responsável pela liberação de bilhões de dólares ao Irã ao remover as sanções, que seriam utilizados para patronizar terroristas, incluindo o Estado Islâmico (PLATAFORMA DO PARTIDO REPUBLICANO, 2016, p. 46). O NSS de 2018 assume a mesma linha, destacando ainda a necessidade da construção de sistemas antimísseis na região iraniana.

Em maio de 2018, agindo de acordo com seu partido e com o apoio de Benjamim Netanyahu, Donald Trump deixou o acordo nuclear iraniano ${ }^{15}$, classificando-o de um "péssimo acordo" que nunca deveria ter sido feito. Trump ainda retomou as sanções impostas à economia iraniana através de uma ordem executiva. Obama declarou que tal ação foi um erro grave por parte de Trump e que os Estados Unidos poderiam ter de escolher, em consequência, entre um Irã nuclear ou outra guerra no Oriente Médio ${ }^{16}$.

Um importante termômetro dos interesses domésticos em política externa são os think tanks. A Heritage Foundation, importante think tank conservador que tem se demonstrado alinhado com a política exterior de Trump, e tradicional defensora do neoconservadorismo, publicou uma série de artigos sobre o acordo nuclear iraniano que são elucidativos para compreender essa corrente da sociedade norte-americana. Antes da saída de Trump do acordo, um artigo publicado pelo think tank afirmava que: "Se o presidente decidir sair do acordo, isso não é nem de longe o fim do mundo- ou até mesmo ruim. Pelo contrário, é um passo necessário para confrontar uma das mais mortais ameaças aos estadunidenses, israelenses e árabes do golfo" (CARAFANO, COFFEY, PHILLIPS, 2018, p. 1).

Em outro artigo publicado pela Heritage Foundation, posteriormente à saída do acordo, Peter Brookes (2010) advogou que Trump tomou a decisão correta, dado a fragilidade do acordo e a continuidade do perigo de um Irã nuclear e economicamente forte no médio prazo ${ }^{17}$.

Na contramão da Heritage, a revista Foreign Affairs, do Council on Foreign Relations, outro influente think tank estadunidense, de viés mais democrata, criticou a postura de Trump. Antes da decisão presidencial, um artigo de Peter Harrell (2018), advertia que o unilateralismo da postura do governo com relação ao acordo dificultaria em muito a eficácia das posteriores sanções planejadas por Trump. Dado que o setor privado, e países como a Rússia e a China, ofereceriam resistência em apoiar os Estados Unidos no boicote, haja vista o aspecto multilateral do JPCA. Seyed Hossein Mousavian (2018), em artigo também publicado pela Foreign Affairs, chamou a saída do acordo de um desastre estratégico, que aproximaria o Irã da Rússia e da China e desestabilizaria ainda mais o Oriente Médio. Sayed afirmou ainda que "quaisquer que foram os motivos para a saída de Trump do acordo, uma estratégia geopolítica sólida não é um deles" (MOUSAVIAN, 2018, p. 2). 
Outro aspecto que pode marcar significativamente a formulação de política externa é a opinião pública. A opinião pública não é somente importante pelo ciclo eleitoral e apoio ao governo, mas também é reveladora de quais elites domésticas estão tendo maior sucesso em pautar a agenda. Em um estudo publicado pela Gallup, em agosto de 2015, apenas um terço da população apoiava a condução do governo Obama em relação ao Irã ${ }^{18}$. Outro estudo, publicado pela mesma agência em fevereiro de $2016^{19}$, apontava que apenas $14 \%$ dos cidadãos possuíam uma visão favorável do Irã e $30 \%$ apoiavam o acordo nuclear iraniano. Com base na filiação partidária, somente $9 \%$ dos republicanos aprovavam o acordo versus o apoio de $51 \%$ dos democratas com relação ao JPCA.

Alguns membros do alto escalão e suas origens também são elucidativos. O primeiro Secretário de Estado nomeado por Trump foi Rex Tillerson, Cheaf Executive Officer (CEO) da Exxon-Mobil. Tillerson foi recentemente substituído por Mike Pompeo, Diretor da CIA. O Secretário do Tesouro escolhido por Trump foi Steve Mnuchin, executivo da Goldman Sachs. Para a Defesa, Trump optou por um General de longa carreira, Jim Mattis. Outros nomes relevantes são o Secretário de Comércio, Wilbur Ross, importante bilionário do setor industrial, e o National Security Advisor John Bolton, um nome respeitado da "linha dura" do Partido Republicano. No gabinete de Donald Trump estão representados os principais grupos de interesse identificados por Mills em sua análise das elites nos Estados Unidos. Entretanto, nem sempre há a coesão necessária entre os grupos e mesmo os membros do governo para implementar políticas. No caso do Irã, por exemplo, conforme recentemente apontado por artigo da Foreign Policy (PERRY, 2018, p. 1-5), John Bolton vem defendendo uma intervenção militar Irã enquanto Jim Mattis está muito mais cauteloso. Bolton já indicou membros para o NSC que compartilham de sua visão. Recentemente, Trump endureceu o tom com o Irã ${ }^{20}$, afirmando que se o país ameaçasse novamente os Estados Unidos, eles iriam sofrer "consequências que poucos sofreram na história".

À guisa da conclusão do presente tópico, o caso do Irã é revelador em diferentes aspectos. A natureza do regime iraniano ameaça interesses vitais das elites estadunidenses. Em especial, aquelas ligadas ao petróleo e a "linha dura" com tendência mais militarista. O Irã é uma potência regional e, por consequência, compete com Israel e Arábia Saudita, dois importantes aliados de Washington. A comunidade judaica nos Estados Unidos é muito forte e realiza lobbie continuo no Congresso e na Casa Branca em defesa dos interesses de Israel. Por mais que a atuação em política externa se concentre mais no executivo, o sucesso de grupos de interesse, organizados através de lobbies e think tanks e a falta de apoio congressual do governo Obama "domesticam" a questão e pendem a resolução da questão iraniana em prol do projeto neoconservador para o país. Tal fato está refletido na opinião pública com relação ao Irã e ao acordo firmado por Obama. A fragilidade do JCPA, que permitiu a inversão de política externa por parte de Trump, pode ser explicada através dessas variáveis domésticas. O mesmo pode ser visto em outras áreas da política exterior de Obama, revelando forte correlação entre a coesão das elites domésticas e a possibilidade de implementar uma agenda de política externa.
18. Disponível em: < https://news. gallup.com/poll/184604/obama-gets-low-marks-handling-iran.aspx>. Acesso em: 16 de jun. 2018.

19. Disponível em: <https://news. gallup.com/poll/189272/after-nuclear-deal-views-iran-remain-dismal.aspx>. Acesso em: 17 de jun. 2018.

20. Ver mais em: https://www. newyorker.com/news/news-desk/trump-threatens-showdown-with-iran. 
Considerações Finais

O presente estudo buscou explicar as diferenças da política externa estadunidense para com o Irã entre os governos de Obama e Donald Trump. Para tal, no entanto, dedicou-se o primeiro tópico para realizar uma discussão e revisão da literatura da área de Análise de Política Externa. Observou-se que variáveis domésticas são fundamentais para analisar a política externa. Diversos estudos na área apontam uma diversidade de variáveis domésticas a serem levadas em consideração. No entanto, optou-se por focar o estudo nos grupos de interesse que podem influenciar de maneira concreta no processo de tomada de decisão na política externa. A contribuição da Ciência Política, com os conceitos da Teoria das Elites e a análise das minorias feita por Giovanni Sartori, complementou o quadro conceitual do presente artigo.

No segundo tópico, adentrou-se na análise empírica da política externa dos dois governos. Dada a extensão do objeto, optou-se por apenas delimitar as principais diretrizes e ações dos dois governos e suas respectivas políticas externas, através da análise dos principais documentos partidários e da Casa Branca. Buscou-se identificar grupos de interesse que influenciavam o processo decisório. Observou-se que, embora o governo Obama tenha buscado avançar em diferentes áreas em sua atuação internacional, suas conquistas foram simbólicas, na medida em que, sem apoio suficiente no cenário doméstico, foram rapidamente revertidas por Donald Trump. A oposição doméstica, que de certa forma "congelou" a política externa de Obama, era constituída por grupos de interesse que, em grande parte, apoiaram a ascensão do Partido Republicano à Casa Branca, através de Trump. Grupos ligados ao pensamento neoconservador constituem importante força política dentro do governo Trump. Além disso, grupos de interesse como o lobby judaico e outros de base mais material, ligados a indústrias tradicionais dos Estados Unidos, impuseram importantes limitações a atuação de Obama.

O terceiro tópico foi dedicado ao estudo de caso do Irã. Os insights providos pela comparação dos dois governos em termos mais gerais, realizado no tópico anterior, provaram-se também verdadeiros na análise da política externa para com o Irã. O JCPA conquistado em um esforço multilateral liderado por Obama, jamais foi ratificado pelo Congresso dos Estados Unidos. Donald Trump, alicerçado no apoio do Partido Republicano e de diversos grupos de interesse, rapidamente retirou os Estados Unidos do acordo. Conforme revelado por diversos documentos do Partido Republicano, de discursos de Trump e de seu gabinete, bem como nas posições emitidas por think tanks, há uma reversão clara no tratamento da questão iraniana por parte do governo Trump com relação ao seu antecessor. Essa reversão pode ser explicada pela atuação dos grupos de interesse.

A hipótese defendida pelo presente estudo, de que a variação da política externa com relação ao Irã, entre os governos Obama e Trump, é explicada pela atuação dos grupos de interesse, foi corroborada pela análise empírica e revisão de literatura. Identificou-se que os principais grupos de interesse que ao mesmo tempo limitaram a realização da agenda de Obama, constituíram a base de apoio doméstica necessária para 
Trump reverter a política externa de seu antecessor. Dito isso, espera-se que esse modesto estudo tenha contribuído para compreender a política externa de Obama e Trump e, em especial, a relação dos Estados Unidos com o Irã no período estudado. A análise dos grupos de interesse pode, portanto, contribuir para uma maior compreensão dos determinantes da política externa. As limitações do presente estudo estão ligadas ao fato de que os eventos analisados se situam em um período muito recente e, portanto, novos eventos podem afetar a análise. Ademais, outros estudos de caso são necessários para avançar nos resultados aqui apresentados.

Referências

AL JAZEERA. Timeline: Iran-US relations: A review of important events in Tehran's relationship with Washington. 2009. Disponível em: <https://www.aljazeera.com/FOCUS/IRANAFTERTHEREVOLUTION/2009/02/2009249123962551.HTML>. Acesso em: 19 jun. 2018.

AMERICAN RETHORIC. Obama's First Inaugural Adress. 2009. Disponível em: <http:// www.americanrhetoric.com/speeches/barackobama/barackobamainauguraladdress.htm $>$. Acesso em: 19 jun. 2018.

AMERICAN RETHORIC. Obama's nomination acceptance speech. 2008. Disponível em: $<$ http://www.americanrhetoric.com/speeches/convention2008/barackobama2008dnc.htm>. Acesso em: 18 jun. 2018.

AMERICAN RETHORIC. Security Team Announcment. 2009. Disponível em: <http://www. americanrhetoric.com/speeches/barackobama/barackobamasecurityteamannouncement. htm>. Acesso em: 18 jun. 2018.

AMORIM, Celso. Teerã, Ramála e Doha: memórias da política externa ativa e altiva. São Paulo: Benvirá. 2015.

BBC NEWS. Iran Nuclear Deal: Key details. 2019. Disponível em: <https://www.bbc.com/ news/world-middle-east-33521655>. Acesso em: 17 de jun. 2018.

BOBBIO, Norberto. Ensaios sobre a ciência política na Itália. Tradução Luiz Sérgio Henriques. São Paulo: Editora Unesp. 2016.

BROOKES, Peter. Trump Was Right to Terminate the Iran Deal. The Heritage Foundation. 2018. Disponível em: <https://www.heritage.org/middle-east/commentary/trump-was-right-terminate-the-iran-deal>. Acesso em: 20 de jun. 2018

BROWN, Seyom. Faces of power: constancy and change in United States foreign policy from Truman to Obama. New York: Columbia University Press. 2015.

CARAFANO, J. C; COFFEY, L; PHILLIPS, J. The Dangers of Trump Allowing Iran Deal to Continue. The Heritage Foundation. 2018. Disponível em: $<$ https://www.heritage.org/middle-east/commentary/the-dangers-trump-allowing-iran-deal-continue $>$. Acesso em: $17 \mathrm{de}$ jun. 2018.

DREIFUSS, René Armand. A Internacional Capitalista. Estratégias e táticas do empresariado transnacional: 1918-1986. Rio de Janeiro: Espaço e Tempo. 1987.

GALLUP. After Nuclear Deal, U.S. Views of Iran Remain Dismal. 2016. Disponível em: $<$ https://news.gallup.com/poll/189272/after-nuclear-deal-views-iran-remain-dismal.aspx $>$. Acesso em: 17 de jun. 2018.

GALLUP. Obama Gets Low Marks for His Handling of Iran. 2015. Disponível em: <https:// news.gallup.com/poll/184604/obama-gets-low-marks-handling-iran.aspx $>$. Acesso em: 16 de jun. 2018.

HARRELL, Peter. The Challenge of Reinstating Sanctions Against Iran It's Not as Simple as Withdrawing From the JCPOA. Foreign Affairs. 2018. Disponível em: $<$ https://www.foreignaffairs.com/articles/iran/2018-05-04/challenge-reinstating-sanctions-against-iran>. Acesso em: 17 de jun. 2018.

HEATH, Thomas. How a Trump presidency will affect 15 industries. The Washington Post. 2016. Disponível em: <file:///C:/Users/natid/Desktop/gustavo_provisorio/How\%20a\%20 Trump $\% 20$ presidency $\% 20$ will\%20affect $\% 2015 \% 20$ industries $\% 20$ - \%20The $\% 20$ Washington $\% 20$ Post.pdf >. Acesso em: 16 de jun. 2018. 
HUDSON, Valerie M. Foreign policy analysis: classic and contemporary theory. Lanham: Rowman \& Littlefield, 2014.

JERVIS, R. System Effects: complexity in political and social life. New Jersey: Princeton University Press, 1997, p.29-91.

KINCH, Penelope. The US-Iran Relationship: The Impact of Political Identity on Foreign Policy. I.B Tauris \& Co Ltd: 2016

LAIDI, ZAKI. Limited Achievements: Obama’s Foreign Policy. New York: Palgrave Macmillan. 2012

LEFFLER, M. P. Trump's Delusional National Security Strategy. Foreign Affairs. 2017. Disponível em: <https://www.foreignaffairs.com/articles/2017-12-21/trumps-delusional-national-security-strategy>. Acesso em: 15 de jun. 2018.

LISSNER, Rebecca. The National Security Strategy Is Not a Strategy. Foreign Affairs:. 2017. Disponível em: <https://www.foreignaffairs.com/articles/united-states/2017-12-19/national-security-strategy-not-strategy>. Acesso em: 15 de jun. 2017.

MILLIBAND, Ralph. O Estado na Sociedade Capitalista; Tradução de Fanny Tabak. Zahar Editores: Rio de Janeiro. 1982.

MILLS, Charles Wright. A Elite do Poder. Tradução de Waltensir Dutra. Zahar Editores. 2000.

MILNER, Helen V. Interests, Institutions and Information: Domestic Politics and International Relations. Princeton: Pricenton University Press, 1994.

MILNER, Helen V. Sailing the water's edge: the domestic politics of American foreign policy. Princeton: Priceton University Press. 2015.

MINTZ, Alex; DeRouen Jr. Understanding Foreing Policy Decision Making. Nova Iorque: Camdrige University Press. 2010.

MOUSAVIAN, Sayed H. The Strategic Disaster of Leaving the Iran Deal. Foreign Affairs. 2018. Disponível em: <https://www.foreignaffairs.com/articles/iran/2018-05-10/strategic-disaster-leaving-iran-deal>. Acesso em: 15 de jun. 2018.

DALL' AGNOL, Gustavo. A força do neoconservadorismo: há uma Doutrina Trump. Mundorama - Revista de Divulgação Científica em Relações Internacionais. Disponível em: $<$ https:// www.mundorama.net $/ \mathrm{p}=24359>$. Acesso em: 12 jan. 2018.

MURRAY, Donate. Us Foreign Policy and Iran: American-Iranian Relations since the Islamic Revolution. Routledge. 2016.

NATIONAL SECURITY STRATEGY ARCHIVE. NSS 2010. Disponível em: < http://nssarchive.us/national-security-strategy-2010/>. Acesso em: 15 de jun. 2018.

NATIONAL SECURITY STRATEGY ARCHIVE. NSS 2015. Disponível em: <http://nssarchive.us/national-security-strategy-2015/>. Acesso em: 15 de jun. 2018.

OPEN SECRETS. Political Action Commities. 2019. Disponível em: $<$ https://www.opensecrets.org $/$ pacs/index.php?cycle $=2016 \&$ party $=$ A $>$. Acesso em: 14 de jun. 2018.

PERRY, Mark. Matti's Last Stand on Iran. Foreign Affairs. 2018. Disponível em: <https://foreignpolicy.com/2018/06/28/mattiss-last-stand-is-iran/>. Acesso em: 25 de jul. 2018.

PUTNAM, Robert. Diplomacy and Domestic Politics: The Logic of Two-Level Games. International Organization. 1988. p. 427-460.

REPUBLICAN NATIONAL COMMITTIE. Republican Party Platform. 2016. Disponível em: $<$ https://prod-cdnstatic.gop.com/media/documents/DRAFT_12_FINAL[1]-ben_1468872234. pdf $>$. Acesso em: 14 de jun. 2018.

REUTERS. Iran-US relations from from 1953 coup to 2016 sanctions relief. Disponível em: $<$ https://www.reuters.com/article/iran-nuclear-usa-timeline/timeline-u-s-iran-relations-from-1953-coup-to-2016-sanctions-relief-idUSL2N1500R1>. Acesso em: 14 de jun. 2018.

SARTORI, Giovanni. A Teoria da Democracia Revisitada. São Paulo: Editora Ática. 1994.

SCHWELLER. Randall L. Unanswered Threats: Political Constraints on the Balance of Power. Princeton: Princeton University Press. 2006.

SIPRI DataBases. SIPRI Arms Industry Base. Disponível em: <https://www.sipri.org/databases/armsindustry >. Acesso em: 14 de maio 2018.

SIPRI DataBases b. SIPRI Miltary Expendure Database. Disponível em: <https://www.sipri. org/databases/milex>. Acesso em: 14 de maio 2018. 
TEIXEIRA, Carlos Gustavo Poggio. O Pensamento Neoconservador em Política Externa nos Estados Unidos. São Paulo: Editora UNESP, 2010.

THE AMERICAN PRESIDENCY PROJECT. 2008. Democratic Party Platform. Disponível em: <http://www.presidency.ucsb.edu/ws/index.php?pid=78283>. Acesso em: 15 de jun. 2018.

THE GUARDIAN. Iran deal: Trump breaks with European allies over 'horrible, one-sided' nuclear agreement. 2018. Disponível em: <https://www.theguardian.com/world/2018/may/08/ iran-deal-trump-withdraw-us-latest-news-nuclear-agreement $>$. Acesso em: 14 de jun. 2018.

THE NEW YORK TIMES. Trump abandons Nuclear Deal he long sconerd. 2018. Disponível em: <https://www.nytimes.com/2018/05/08/world/middleeast/trump-iran-nuclear-deal. html>. Acesso em: 13 de jun. 2018.

THOMPSON, Loren. For The Defense Industry, Trump's Win Means Happy Days Are Here Again. Forbes. 2016 Disponível em: <https://www.forbes.com/sites/lorenthompson/2016/11/09/for-the-defense-industry-trumps-win-means-happydays- are-here-again/\#57161c80b3c5>. Acesso em: 14 de jun. 2018.

UNITED STATES WHITE HOUSE. National Security Strategy. Disponível em: <https:// www.whitehouse.gov/wp-content/uploads/2017/12/NSSFinal- 12-18-2017-0905.pdf >. Acesso em: 22 dez. 2017.

WALTZ, Kenneth. Theory of international politics. New York: McGraham Hill, 1979.

WRIGHT, Robin. Trump Threatens a Showdown with Iran. But How? The New Yorker: 2018. Disponível em: <https://www.newyorker.com/news/news-desk/trump-threatens-showdown-with-iran>. Acesso em: 13 de jun. 2018. 